\title{
The Effect of Oketani Breast Massage on Successful Breastfeeding, Mothers' Breastfeeding Support Need, and Breastfeeding Self-Efficacy: A Clinical Trial Study
}

\section{Maryam Mahdizadeh Shahri}

Shahid Beheshti University of Medical Sciences School of Nursing and Midwifery https://orcid.org/0000-0002-3922-9561

Manijeh Nourian ( $\nabla$ nourianma@gmail.com )

Shahid Beheshti University of Medical Sciences School of Nursing and Midwifery

Maryam Varzeshnejad

Shahid Beheshti University of Medical Sciences School of Nursing and Midwifery

Maliheh Nasiri

Shahid Beheshti University of Medical Sciences School of Nursing and Midwifery

\section{Research}

Keywords: Oketani Massage, Cesarean Section, Breastfeeding, Breastfeeding Self-Efficacy, Need for Breastfeeding Support, Breastfeeding Success

Posted Date: August 31st, 2020

DOI: https://doi.org/10.21203/rs.3.rs-64870/v1

License: (c) (1) This work is licensed under a Creative Commons Attribution 4.0 International License.

Read Full License 


\title{
The effect of Oketani breast massage on successful breastfeeding, mothers' breastfeeding support need, and breastfeeding self-efficacy: A clinical trial study
}

\author{
Maryam Mahdizadeh Shahri ${ }^{1}$, Manijeh Nourian², Maryam Varzeshnejad ${ }^{3}$, Maliheh Nasiri ${ }^{4}$
}

\begin{abstract}
Background: The most important factor in the survival and health of infants is breastfeeding. One of the complications of cesarean sections is their negative effect on the quality of breastfeeding. This study aimed to determine the effect of Oketani breast massage on the maternal need for support during breastfeeding, breastfeeding success, and breastfeeding selfefficacy.

Methods: The research sample in this clinical trial study included pregnant women who referred to Mahdiyeh, Taleghani, and Imam Hossein hospitals as candidates for a cesarean section. The mothers were selected using convenience sampling and randomly assigned to the intervention group $(\mathrm{n}=55)$ and the control group $(\mathrm{n}=58)$. The data were collected using, the Infant Breastfeeding Assessment Tool (IBFAT), the Breastfeeding Charting System (LATCH), and the Breastfeeding Self-Efficacy Scale (BSES). To assess the breastfeeding success rate, the number of breastfeeding times, and the onset time of the first breastfeeding were recorded. The collected data were analyzed using SPSS software (version 20) via the independent samples $t$-test, the Mann-Whitney $\mathrm{U}$ test, and chi-square test.

Results: The results of the study suggested that the breastfeeding success rate in both the first two breastfeeding stages and the last pre-discharge breastfeeding was significantly higher for the participants in the intervention group than the members of the control group ( $\mathrm{p}<0.001)$. Besides, the mother's need for support in the first two breastfeeding stages $(\mathrm{p}=0.044)$ and the last pre-discharge breastfeeding $(\mathrm{p}<0.001)$ in the intervention group was less than that of the mothers in the control group. The number of breastfeeding in the intervention group was higher than the control group $(\mathrm{p}=0.002)$. Furthermore, the mothers in the intervention group breastfed their infants in a significantly less time interval $(p=0.002)$. The breastfeeding self-efficacy was significantly higher in the intervention group than in the control group $(\mathrm{p}<0.001)$.
\end{abstract}

Conclusion: Oketani massage can be used as a care intervention by nurses to improve breastfeeding in mothers who undergo cesarean sections and have more breastfeeding problems.

\section{Trial registration}

Iranian Registry of Clinical Trials (IRCT): IRCT20190129042542N1.

Keywords: Oketani Massage, Cesarean Section, Breastfeeding, Breastfeeding Self-Efficacy, Need for Breastfeeding Support, Breastfeeding Success

\footnotetext{
${ }^{1}$ Master Student in Neonatal Intensive Care Nursing, School of Nursing and Midwifery, Shahid Beheshti University of Medical Sciences, Tehran, Iran. Tel: +989124741864, E-mail: m.mahdizadeh.sh@ gmail.com

${ }^{2}$ Assistant Professor, Department of Pediatric and Neonatal Nursing, School of Nursing and Midwifery, Shahid Beheshti University of Medical Sciences, Tehran, Iran. (Corresponding author) Tel+989125446122, E-mail: nourianma@ gmail.com ${ }^{3}$ Assistant Professor, Department of Pediatric and Neonatal Nursing, School of Nursing and Midwifery, Shahid Beheshti University of Medical Sciences, Tehran, Iran. Tel: +98916388957, E-mail: $\underline{\text { m.varzeshnejad@gmail.com }}$

${ }^{4}$ Assistant Professor, Department of Pediatric and Neonatal Nursing, School of Nursing and Midwifery, Shahid Beheshti University of Medical Sciences, Tehran, Iran. Tel: +989177204642, E-mail: malihenasiri@gmail.com
} 


\section{Background}

Despite global efforts to promote natural childbirth, the rate of non-emergency cesarean sections is increasing, especially in developing countries (1). In Iran, the number of cesarean sections is much higher than the world standard (2) to the extent that it has reached more than $54.8 \%$ in some areas (1). However, the rate of cesarean sections in each region should not exceed $10 \%$ to $15 \%$ (1). The growing and excessive increase of cesarean sections and its negative effects on breastfeeding success and duration of breastfeeding have become a global concern $(1,3)$.

One of the important complications of cesarean sections is their negative impact on breastfeeding success (1). Successful breastfeeding means the successful transfer of milk from the mother's breast to the baby's mouth, which is influenced by several factors such as the infant's desire to receive milk, hearing the sound of a baby swallowing milk, the number of breastfeeding between 8 and 12 times a day, and the emptiness and softness of mother's breasts after each breastfeeding (4). In cesarean sections, due to the long-term separation of the mother and baby, the lack of skin-to-skin contact, and pain caused by surgery, there is a delay in starting breastfeeding and the success and exclusive continuation of breastfeeding is reduced, so that these mothers need more support for breastfeeding especially during the first hours and days after birth $(5,6)$. Furthermore, mothers who undergo cesarean sections are less interested in breastfeeding their babies and also their babies show less effort to be breastfed early during the first 24 hours of birth, and this reduces the mother's chance for successful breastfeeding (7) and increases the likelihood of milk accumulation and breast congestion (8).

While the World Health Organization (WHO) and UNICEF emphasize early breastfeeding within half to one hour of birth and its exclusive continuation for at least six months (1), the onset of breastfeeding is delayed for a longer time for neonates born by cesarean sections compared to those born via normal delivery $(3,5,6)$. This may reduce the baby's acceptance of the breast and the baby's sucking reflex and have a negative effect on the development of the baby's neurological system (7). One of the most important and influential factors on successful breastfeeding and its self-efficacy is the type of delivery. By increasing the time to start the first breastfeeding, early and long-term separation of mother and baby, and the 
mother's greater need for support for breastfeeding and its onset, cesarean sections reduce the mother's sense of self-sufficiency, ability, and self-esteem and prevent the success and continuation of breastfeeding $(3,6)$. Cesarean sections increase the mother's need for support during breastfeeding and reduce her breastfeeding self-efficacy (9).

Breastfeeding self-efficacy is defined as the mother's perceived ability to breastfeed and her self-confidence in her ability to breastfeed the baby successfully (3, 10). Low levels of breastfeeding self-efficacy are associated with an increased probability of early cessation of exclusive breastfeeding (11). Nevertheless, breastfeeding self-efficacy has shown a significant and positive relationship with increasing the breastfeeding duration $(6,9)$ and is considered as one of the important indicators influencing breastfeeding outcomes $(12,13)$. In general, cesarean sections can affect mothers' need for breastfeeding support and breastfeeding self-efficacy by causing devastating effects on three breastfeeding success factors $(1,9,10)$. Besides, given the numerous problems suffered by cesarean section mothers as detailed above, it is necessary to take intervention measures to reduce these problems and improve breastfeeding. Accordingly, one of the standard nursing interventions mentioned in the Nursing Interventions Classification (NIC) is massage therapy. Massage therapy has been used in various fields, and a subtype of massage therapy is Oketani breast massage (46).

Oketani breast massage is an efficient, cost-effective, and easy method $(8,14,15)$ that was first introduced as a massage technique in 1981 in Japan by Sotomi Oketani $(15,16)$. Studies have underlined the positive effect of this type of massage on reducing breast pain, increasing the speed of infant sucking $(14,17)$, improving the quality of breast milk by increasing $\mathrm{pH}$ (14), increasing lipids at the end of feeding (18), reducing sodium in breast milk (14), increasing infant weight gain (8), and reducing breast congestion in different communities (19). Previous studies have addressed eligible breastfeeding mothers including mothers with normal delivery and cesarean sections regardless of the breastfeeding interval and time, and none of the studies specifically focused on breastfeeding mothers who were candidates for cesarean sections.

Since the most important factor for the survival and health of infants is breastfeeding, and the first environment to start breastfeeding is the hospital environment $(20,21)$. Given the 
importance of the role played by nurses in supporting, educating, and promoting breastfeeding. considering that Oketani massage is a low-cost, independent nursing intervention; and finally, concerning the breastfeeding problems faced by cesarean section mothers $(8,21,46)$, the present study explored the effect of Oketani breast massage on the need for support during breastfeeding, breastfeeding success, and breastfeeding self-efficacy among mothers undergoing caesarian section.

\section{Methods}

This study was a clinical trial study and was performed in two intervention and control groups. The research population included all pregnant women who referred to Mahdiyeh, Taleghani, and Imam Hossein hospitals in Tehran as candidates for cesarean sections.

The inclusion criteria were being at the age of 18 to 35 years, singleton pregnancy, absence of physical and mental illness that prevents breastfeeding based on the available medical records, gestational age of 38 to 42 weeks, no history of breast surgery and breast tumor, the absence of disorders such as placental abruption, placenta previa, heart and respiratory diseases during pregnancy, lack of hepatitis and AIDS during pregnancy and after, the birth of a healthy and mature baby weighing more than 2500 grams, the first- and fifth-minute Apgar score of above 7, the absence of the need for any postnatal medical intervention based on the medical records, and the absence of any cleft palate and cleft lip in the infant.

The exclusion criteria were as follows: Having infants in need of intensive care at birth or admitted to the neonatal intensive care unit, severe bleeding, atony or uterine inertia during cesarean sections, use of any drug that stopped breastfeeding, the existence of any reason that led to a ban on breastfeeding, the unwillingness to breastfeed the baby or participate in the study, and the mothers who were discharged 24 hours before starting the study upon their consent and did not receive any massage treatment.

The sample size was calculated as equal to 44 persons per group following a similar study (22) and according to the equation presented below with $95 \%$ confidence and $80 \%$ power. Besides, considering the participants' dropout, at least 50 mothers were selected as the members of each group. 


$$
n \geq 2 \frac{\left(z_{\alpha / 2}+z_{\beta}\right)^{2} \sigma^{2}}{\left(\mu_{1}-\mu_{2}\right)^{2}}
$$

The mothers were selected using convenience sampling and randomly assigned to the intervention and control groups. To prevent contact between mothers in the two groups, sampling was performed in each hospital every other week (from Saturday to Wednesday). To this end, by drawing lots, each mother was assigned randomly to a group in the first week, and accordingly, the participants were assigned to either the intervention or control groups in the alternative weeks. The sampling procedure was performed from April to July 21, 2019. The mothers completed the demographic characteristics questionnaire before entering the operating room. Besides, the researcher completed the neonatal section of the questionnaire after the infants' birth in the operating room.

The mothers in the control group received routine care. Including; measuring the baby's height and chest circumference, dressing the baby with the help of an attendant, and transferring him/her to the mother's room under the supervision of a nurse, and teaching breastfeeding verbally, as well as the nurse's emphasis on timely breastfeeding and instruction on how to care for the baby while breastfeeding. The mothers in the intervention group, in addition to receiving routine care, underwent Oketani breast massage by the researcher twice before the mother entered the operating room and once before the mother's first breastfeeding in the recovery room or the ward. Before starting the intervention in both stages, the researcher did her best to maintain the participants' privacy and protect their personal territory and space according to the requirements of the hospital and the ward. To this end, she pulled the curtains around the mothers and performed Oketani massage on the massage site using a cotton towel. She also gave the mothers a package containing a cotton towel (to cover the massage site), a training brochure about Oketani massage and its benefits, and gloves. Besides, adequate explanations gave to the mothers orally on how to perform the massage. Oketani breast massage included eight manual techniques performed within 60 sec and repeated for 15-20 min. Levels 1-3 of the given therapy were associated with the detachment of the bottom of the breast from its pectoralis major muscle. Furthermore, levels 4-6 involved pulling the whole breast with two thumbs down and to both sides by both hands. Additionally, level 7 included rotating the breast gently clockwise with stretching of its base, 
and level 8 was about milking the breast in four different directions. The researcher in both right and left breasts performed Oketani massage. During the first massaging stage, the researcher talked to the mother about the benefits of breast milk, its early onset and how the massage mechanism, helps to breastfeed. During the second massaging stage, the researcher discussed how to breastfeed the baby and helped the mother to do it effectively. The massage therapy was performed on all mothers by the first author after gaining the necessary training and skills under the supervision of a complementary medicine physician. Blinding was not possible due to the nature of the study.

The breastfeeding success rate and mother's need for support during breastfeeding were measured and recorded once in the first breastfeeding and once during the last breastfeeding (22 to 28 hours after cesarean sections) for all mothers in both intervention and control groups before discharge. The Breastfeeding Self-Efficacy Scale (BSES) was completed by the mothers themselves once after the last breastfeeding. The number of breastfeeding times from birth to the last breastfeeding before discharge was recorded by the researcher.

The following instruments were used to collect the data:

1. The Demographic Characteristics Questionnaire: The questionnaire contained two maternal and neonatal sections.

2. The Breastfeeding Charting System (LATCH): This tool was elaborated in 1994 in the USA by a nurse called Deborah Jensen and her group to document the assessment of breastfeeding $(5,6,23)$. The total score gained by administering this tool varies from zero to ten and getting a score of less than ten shows the mother's need for more support during breastfeeding. The letters of the acronym LATCH designate separate areas of assessment. L (Latch) for how well the infant's latch in the breast, A (Audible swallowing) refers to the amount of audible swallowing noted while nursing the baby, T (Type of nipple) for the mother's nipple type, C (Comfort) for the mother's level of comfort relation to the breast and nipple, $\mathrm{H}$ (Hold) refers to whether or not the mother needs help in positioning the child. The system assigns a numerical score, 0,1 , or 2 , to five key statements (23). The validity and reliability of this tool have been reviewed and confirmed in several studies (5, 23-25). Karimi et al. (2009) assessed the reliability of the tool using the Cronbach's alpha coefficient and the corresponding value was reported as $0.711(26)$. The reliability of this tool was evaluated in 
the present study using concurrent observation of 15 mothers and its Cronbach's alpha coefficient was calculated to be 0.98 .

3. The Infant Breastfeeding Assessment Tool (IBFAT): The IBFAT contains four scored items assessing the infant state: (1) infant readiness to feed/arousability, (2) rooting, (3) fixing (time needed to latch to the breast) and (4) sucking pattern. Each item is scored on a scale of $0-3$, with the minimum and maximum scores of 0 to 12 , respectively. A score of 1012 indicates completely successful breastfeeding, a score of 7-9 suggests relatively successful breastfeeding, and a score of $0-6$ shows unsuccessful breastfeeding $(27,47)$. This tool has been used in various studies in Iranian society and its validity and reliability have been confirmed (28-30). In the present study, the reliability of this tool was calculated to be 0.97 by concurrent observation of 15 participating mothers.

The LATCH tool, which is a system for the documentation of lactation, identifies areas where intervention is required to support lactancy and focuses on the role of the mother in the process of breastfeeding whereas the IBFAT scale focuses on the baby during feeding (48).

4. The Breastfeeding Self-Efficacy Scale-Short Form (BSES-SF): This scale was developed by Dennis (2003) and contains 14 statements $(9,31)$ that are scored on a 5-point Likert scale ranging from very confident (score 5) to never confident (score 1). The minimum and maximum possible scores on this scale are 14 and 70, respectively. In a study conducted in Iran by Arab et al. (2014), Cronbach's alpha coefficient of the scale was reported to be more than 0.7 (32). In various foreign studies, the Cronbach's alpha coefficient of this instrument was reported from 0.86 to $0.94(6,33)$. The internal consistency of the scale was estimated to be 0.94 in the present study.

This study was extracted from a master's thesis approved by Shahid Beheshti University of Medical Sciences under the code of ethics IR.SBMU.PHARMACY.REC.1399.110 and the Iranian Registry of Clinical Trials registration code IRCT20190129042542NI. The objectives of the study were explained to all participants and written consent was obtained from them. The participants were reassured that the information would be kept confidential and that they had the right to leave the study at any time they wished. 
The collected data were analyzed using SPSS software (version 20) via descriptive statistics (mean, standard deviation, frequency, and percentage) and inferential statistics including the independent samples t-test, the Mann-Whitney U test, and chi-square test.

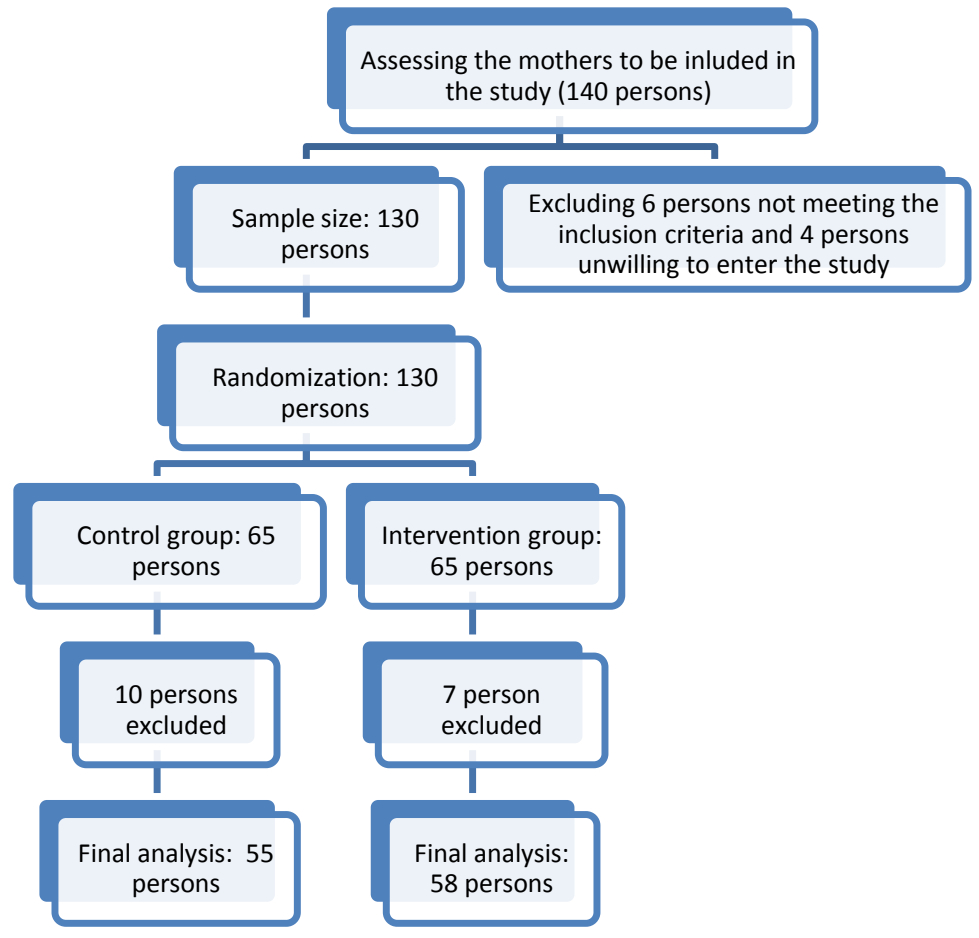

Figure 1: The participants' selection flowchart

\section{Results}

In this study, Oketani massage was taken as the independent variable and the breastfeeding success rate, the mother's need for support during breastfeeding, and the mother's breastfeeding self-efficacy were manipulated as the dependent variables. To accurately assess the breastfeeding success rate, the number of breastfeeding times, and the onset time of the first breastfeeding were recorded and evaluated. The results showed that the mean age of the participants in the intervention and control groups was $29.85 \pm 4.43$ and $28.95 \pm 5.33$ years, respectively. There was no statistically significant difference between the two groups in terms of demographic characteristics of the mothers and their infants (Table 1). It was also shown that in both breastfeeding rounds (the first and last breastfeeding before discharge), the number of mothers with completely successful breastfeeding in the intervention group was significantly higher than those in the control group $(p<0.001)$ (Table 2). Furthermore, it was noted that the mean scores for all dimensions of breastfeeding 
success including readiness to feed, rooting, fixing (latching on), and sucking in breastfeeding mothers in the intervention group in both stages were significantly higher than those of the participants in the control group $(\mathrm{p}<0.001)$.

The results of the study concerning the need for breastfeeding support suggested a statistically significant difference between the two groups in both breastfeeding rounds. The mothers in the intervention groups needed less support compared to the participants in the control group $(\mathrm{p}<0.001)$ (Table 2). It was also shown that the number of breastfeeding times for the participants in the intervention group from the time of entry to the recovery room to discharge was higher compared to that of the participants in the control group $(\mathrm{p}<<0.001)$. Besides, the mothers in the intervention group breastfed their infants within less than one hour after entering the recovery room, showing a significant difference in comparison with the participants in the control group $(\mathrm{p}<0.002)$. The results also indicated that the breastfeeding self-efficacy of the mothers in the intervention group was significantly higher than those in the control group $(\mathrm{p}<0.001)$ (Table 3):

Table 1: A comparison of the demographic characteristics of the participants in the two groups

\begin{tabular}{|l|l|l|l|l|l|}
\hline Variables & Categories & \multicolumn{2}{|l|}{ Groups } & P-value & Statistic \\
\cline { 3 - 6 } & & $\begin{array}{l}\text { Intervention } \\
(\text { Mean } \pm \text { SD) }\end{array}$ & $\begin{array}{l}\text { Control } \\
(\text { Mean } \pm \text { SD) }\end{array}$ & & s \\
\hline \multirow{2}{*}{$\begin{array}{l}\text { Maternal } \\
\text { and neonatal } \\
\text { data }\end{array}$} & Maternal age & $29.85 \pm 4.43$ & $28.95 \pm 5.33$ & $* 0.33$ & 0.98 \\
\cline { 2 - 6 } & Gestational age & $38.42 \pm 0.71$ & $38.52 \pm 1.06$ & $* 0.56$ & 0.58 \\
\cline { 2 - 6 } & Infant's height & $49.81 \pm 2.22$ & $50.03 \pm 2.24$ & $* 0.608$ & 0.51 \\
\cline { 2 - 5 } & $\begin{array}{l}\text { Infant's chest } \\
\text { circumference }\end{array}$ & $33.36 \pm 0.78$ & $33.17 \pm 1.12$ & $* 0.300$ & 1.04 \\
\hline
\end{tabular}




\begin{tabular}{|c|c|c|c|c|c|}
\hline & $\begin{array}{l}\text { Infant's head } \\
\text { circumference }\end{array}$ & $34.76 \pm 0.89$ & $34.61 \pm 1.14$ & $* 0.436$ & 0.78 \\
\hline & Infant's weight & $\begin{array}{l}3245.9 \pm 323.6 \\
4\end{array}$ & $\begin{array}{l}3248.1 \pm 469.1 \\
7\end{array}$ & $* 0.977$ & 0.03 \\
\hline & $\begin{array}{l}\text { Apgar (First } \\
\text { minute) }\end{array}$ & $9.00 \pm 0.00$ & $8.97 \pm 0.26$ & $* 0.332$ & 0.97 \\
\hline & $\begin{array}{l}\text { Apgar (Fifth } \\
\text { minute) }\end{array}$ & $10.00 \pm 0.00$ & $9.98 \pm 0.13$ & $* 0.332$ & 0.97 \\
\hline & $\begin{array}{l}\text { Previous } \\
\text { breastfeeding } \\
\text { duration }\end{array}$ & $21.62 \pm 17.45$ & $17.38 \pm 17.50$ & $* 0.20$ & 0.51 \\
\hline \multirow[t]{5}{*}{$\begin{array}{l}\text { Mother's } \\
\text { education }\end{array}$} & Categories & $\mathrm{N}(\%)$ & $\mathrm{N}(\%)$ & P-value & $\begin{array}{l}\text { Statistic } \\
\text { s }\end{array}$ \\
\hline & Illiterate & $3(5.5)$ & $2(3.4)$ & \multirow{4}{*}{$\begin{array}{l}* * * 0.37 \\
7\end{array}$} & \multirow{4}{*}{$\begin{array}{l}1452.00 \\
0\end{array}$} \\
\hline & $\begin{array}{l}\text { Primary/secondar } \\
\text { y school }\end{array}$ & $20(36.4)$ & $27(46.6)$ & & \\
\hline & Diploma & $22(40)$ & $22(37.9)$ & & \\
\hline & Higher education & $20(18.2)$ & $7(12.1)$ & & \\
\hline \multirow[t]{2}{*}{ Occupation } & Employed & $2(3.6)$ & $4(6.9)$ & \multirow[t]{2}{*}{$* * 0.440$} & \multirow[t]{2}{*}{0.435} \\
\hline & Housewife & $53(96.4)$ & $54(93.1)$ & & \\
\hline \multirow{3}{*}{$\begin{array}{l}\text { Household } \\
\text { income }\end{array}$} & Low & $12(21.8)$ & $12(20.7)$ & \multirow{3}{*}{$\begin{array}{l}* * * 0.75 \\
3\end{array}$} & \multirow{3}{*}{$\begin{array}{l}1555.50 \\
0\end{array}$} \\
\hline & Good & $43(78.2)$ & $35(77.6)$ & & \\
\hline & Satisfactory & $0(0.00)$ & $1(1.7)$ & & \\
\hline \multirow{2}{*}{$\begin{array}{l}\text { Place of } \\
\text { residence }\end{array}$} & City & $52(94.5)$ & (53(91.4) & \multirow[t]{2}{*}{$* * 0.512$} & \multirow[t]{2}{*}{0.509} \\
\hline & Rural areas & $3(5.5)$ & $5(8.6)$ & & \\
\hline \multirow{2}{*}{$\begin{array}{l}\text { Pregnancy } \\
\text { planning }\end{array}$} & Yes & $37(67.3)$ & $46(79.3)$ & \multirow[t]{2}{*}{$* * 0.148$} & \multirow[t]{2}{*}{0.147} \\
\hline & No & $18(32.7)$ & $12(20.7)$ & & \\
\hline \multirow{2}{*}{$\begin{array}{l}\text { Number of } \\
\text { pregnancies }\end{array}$} & One & $6(10.9)$ & $10(17.2)$ & \multirow[t]{2}{*}{$* * 0.129$} & \multirow{2}{*}{$\begin{array}{l}1357.50 \\
0\end{array}$} \\
\hline & Two & $28(50.9)$ & $33(56.9)$ & & \\
\hline
\end{tabular}




\begin{tabular}{|c|c|c|c|c|c|}
\hline & Three & $21(38.2)$ & $15(25.9)$ & & \\
\hline \multirow{8}{*}{$\begin{array}{l}\text { Maternal } \\
\text { diseases }\end{array}$} & No disease & $29(52.7)$ & $36(62.1)$ & \multirow[t]{8}{*}{$* * 0.892$} & \multirow[t]{8}{*}{0.854} \\
\hline & Diabetes & $8(14.5)$ & $6(10.3)$ & & \\
\hline & Hypertension & $2 .(36)$ & $3(5.2)$ & & \\
\hline & Hypothyroidism & $12(21.8)$ & $9(15.5)$ & & \\
\hline & $\begin{array}{l}\text { Hypothyroidism } \\
\& \text { diabetes }\end{array}$ & $0(0.00)$ & $1(1.7)$ & & \\
\hline & $\begin{array}{l}\text { Hypertension \& } \\
\text { diabetes }\end{array}$ & $1(1.8)$ & $1(1.7)$ & & \\
\hline & $\begin{array}{l}\text { Hypertension \& } \\
\text { hypothyroidism }\end{array}$ & $1(1.8)$ & $1(1.7)$ & & \\
\hline & Other diseases & $1(1.8)$ & $1(1.7)$ & & \\
\hline \multirow{2}{*}{$\begin{array}{l}\text { Neonatal } \\
\text { gender }\end{array}$} & Female & $25(45.5)$ & $21(36.2)$ & \multirow[t]{2}{*}{$* * 0.317$} & \multirow[t]{2}{*}{0.317} \\
\hline & Male & $30(54.5)$ & $37(63.8)$ & & \\
\hline \multirow{3}{*}{$\begin{array}{l}\text { Breastfeedin } \\
\text { g decision }\end{array}$} & Exclusive & $50(90.9)$ & $46(79.3)$ & \multirow[t]{3}{*}{$* * 0.188$} & \multirow[t]{3}{*}{0.151} \\
\hline & Non-inclusive & $(0.00)$ & $1(1.7)$ & & \\
\hline & Mixed & $5(9.1)$ & 11(19.00) & & \\
\hline \multirow{3}{*}{$\begin{array}{l}\text { Type of } \\
\text { anesthesia }\end{array}$} & General & $4(7.3)$ & $1(1.7)$ & \multirow[t]{3}{*}{$* * 0.152$} & \multirow[t]{3}{*}{0.140} \\
\hline & Spinal & $51(92.7)$ & $57(98.3)$ & & \\
\hline & Epidural & $0(0.00)$ & $0(0.00)$ & & \\
\hline
\end{tabular}

*: Independent samples t-test, **: Chi-square test, ***: Mann-Whitney U test

Table 2: A comparison of the two groups according to the mother's need for breastfeeding support and breastfeeding success

\begin{tabular}{|l|l|l|l|l|l|}
\hline Breastfeeding phase & \multicolumn{2}{l|}{$\begin{array}{l}\text { The first breastfeeding (after } \\
\text { surgery) }\end{array}$} & \multicolumn{2}{l|}{$\begin{array}{l}\text { The last breastfeeding (before } \\
\text { discharge) }\end{array}$} \\
\hline Groups & $\begin{array}{l}\text { Intervention } \\
(\mathrm{n}=55)\end{array}$ & $\begin{array}{l}\text { Control }(\mathrm{n} \\
=58)\end{array}$ & $\begin{array}{l}\text { Interventio } \\
\mathrm{n}(\mathrm{n}=55)\end{array}$ & $\begin{array}{l}\text { Control (n } \\
=58)\end{array}$ & P-value \\
& &
\end{tabular}




\begin{tabular}{|c|c|c|c|c|c|c|c|c|c|c|c|}
\hline \multicolumn{2}{|l|}{ Variables } & \multirow{2}{*}{$\begin{array}{l}\mathrm{Nu} \\
\mathrm{mb} \\
\mathrm{er} \\
49\end{array}$} & \multirow{2}{*}{$\begin{array}{l}\% \\
89.1\end{array}$} & \multirow{2}{*}{$\begin{array}{l}\mathrm{Nu} \\
\mathrm{mb} \\
\text { er } \\
57\end{array}$} & \multirow{2}{*}{$\begin{array}{l}\% \\
98.3\end{array}$} & \multirow{2}{*}{$\begin{array}{l}\mathrm{P}- \\
\text { valu } \\
\mathrm{e} \\
{ }^{*} 0.0 \\
44\end{array}$} & \multirow{2}{*}{$\begin{array}{l}\text { Num } \\
\text { ber }\end{array}$} & \multirow{2}{*}{$\begin{array}{l}\% \\
21 . \\
8\end{array}$} & \multirow{2}{*}{$\begin{array}{l}\text { Num } \\
\text { ber }\end{array}$} & \multirow{2}{*}{$\begin{array}{l}\% \\
\\
70 . \\
7\end{array}$} & \multirow{2}{*}{$*<0.001$} \\
\hline $\begin{array}{l}\text { Need for } \\
\text { breastfeedin }\end{array}$ & Need for support & & & & & & & & & & \\
\hline \multirow[t]{2}{*}{ g support } & $\begin{array}{l}\text { No need for } \\
\text { support }\end{array}$ & 6 & 10.9 & 1 & 1.7 & & 43 & $\begin{array}{l}78 . \\
2\end{array}$ & 17 & $\begin{array}{l}29 . \\
3\end{array}$ & \\
\hline & Total & 55 & 100 & 58 & 100 & & 55 & $\begin{array}{l}10 \\
0\end{array}$ & 58 & $\begin{array}{l}10 \\
0\end{array}$ & \\
\hline \multirow{4}{*}{$\begin{array}{l}\text { Breastfeedi } \\
\text { ng success } \\
\text { score }\end{array}$} & $\begin{array}{l}\text { 10-12 } \\
\text { (Successful) }\end{array}$ & 37 & 67.3 & 18 & 31 & \multirow[t]{4}{*}{$\begin{array}{l}*<0 . \\
001\end{array}$} & 49 & $\begin{array}{l}89 . \\
1\end{array}$ & 26 & $\begin{array}{l}44 . \\
8\end{array}$ & \multirow[t]{4}{*}{$*<0.001$} \\
\hline & $\begin{array}{l}\text { 7-9 (Relatively } \\
\text { successful) }\end{array}$ & 14 & 25.5 & 12 & 20.7 & & 5 & 9.1 & 19 & $\begin{array}{l}32 . \\
8\end{array}$ & \\
\hline & $\begin{array}{l}0-6 \\
\text { (Unsuccessful) }\end{array}$ & 4 & 7.3 & 28 & 48.3 & & 1 & $\begin{array}{l}1.1 \\
8\end{array}$ & 13 & $\begin{array}{l}22 . \\
4\end{array}$ & \\
\hline & Total & 55 & 100 & 58 & 100 & & 55 & $\begin{array}{l}10 \\
0\end{array}$ & 58 & $\begin{array}{l}10 \\
0\end{array}$ & \\
\hline
\end{tabular}

*: Mann-Whitney U test

Table 3: A comparison of the two groups in terms of the frequency of breastfeeding, the time of the first breastfeeding, and the mother's self-efficacy

\begin{tabular}{|c|c|c|c|c|c|c|}
\hline \multicolumn{2}{|l|}{ Variables } & \multicolumn{4}{|c|}{ Groups } & \multirow[t]{3}{*}{ P-value } \\
\hline & & \multicolumn{2}{|c|}{ Intervention } & \multicolumn{2}{|l|}{ Control } & \\
\hline & & Number & $\%$ & Number & $\%$ & \\
\hline \multirow[t]{3}{*}{$\begin{array}{l}\text { The number of breastfeeding from the } \\
\text { entry to the recovery room until discharge }\end{array}$} & $\begin{array}{l}\text { Less than } 10 \\
\text { times }\end{array}$ & 19 & $\begin{array}{l}34 . \\
5\end{array}$ & 37 & $\begin{array}{l}63 . \\
8\end{array}$ & \multirow[t]{3}{*}{$* 0.002$} \\
\hline & $\begin{array}{l}10 \text { times and } \\
\text { more }\end{array}$ & 36 & $\begin{array}{l}65 . \\
5\end{array}$ & 21 & $\begin{array}{l}36 . \\
2\end{array}$ & \\
\hline & Total & 55 & 10 & 58 & $\begin{array}{l}10 \\
0\end{array}$ & \\
\hline
\end{tabular}




\begin{tabular}{|l|l|l|l|l|l|l|}
\hline $\begin{array}{l}\text { The time of the first breastfeeding after } \\
\text { the entry to the recovery room }\end{array}$ & $\begin{array}{l}\text { Less than 1 } \\
\text { hour }\end{array}$ & 35 & $\begin{array}{l}63 . \\
6\end{array}$ & 20 & 34. & $* 0.002$ \\
\cline { 2 - 6 } & $\begin{array}{l}\text { More than 1 } \\
\text { hour }\end{array}$ & 20 & $\begin{array}{l}36 . \\
4\end{array}$ & 38 & 65. & \\
\cline { 2 - 7 } & Total & 55 & 10 & 58 & 10 & \\
& & & 0 & & 0 & \\
\hline Breastfeeding self-efficacy (Mean \pm SD) & & & & & & $* *<0.001$ \\
\hline
\end{tabular}

*: Mann-Whitney U test, **: Independent samples t-test

\section{Discussion}

This study explored the effects of Oketani massage on breastfeeding success, the need for breastfeeding support, and breastfeeding self-efficacy among the mothers of term infants born via cesarean sections. The results of the study suggested that Oketani massage has positive effects on the mother's breastfeeding success and can improve it in different respects including readiness to feed, rooting, fixing (latching on), and sucking, as evident in various studies $(8,14,17,19,34)$. Accordingly, Cho et al. (2012) found that Oketani breast massage, in addition to reducing breast pain and increasing the $\mathrm{pH}$ of breast milk, was associated with an increase in sucking speed and breast milk volume and consequently the improved breastfeeding success (14). The authors studied the mothers with any type of delivery and with breastfeeding problems and breast pain, and they did not focus on the problems of cesarean section mothers. Postoperative pain after cesarean sections is one of the reasons for a delay in starting breastfeeding (1) which makes mothers experience more pain in the breast and are more prone to breast congestion $(19,35)$.

Massage can be used as an effective intervention to control mothers' postoperative pain (14, 34, 36). However, each intervention, in addition to its positive effects, is associated with some complications and side effects, including muscle pain, fatigue, and damage to muscle tissue and peripheral nerves in the case of massage therapy $(43,44,45)$. Nevertheless, since 
Oketani massage is based on massaging all the breast muscles, the base, as well as the areola, in addition to affecting blood and lymph flows, can reduce milk stasis in the breast without any unwanted side effects. It can even reduce the pain of breast congestion and increase the mother's success in breastfeeding by stimulating the oxytocin/milk ejection reflex $(8,16$, 19).

The present study showed that Oketani massage had a positive effect on the frequency of breastfeeding so that the average number of breastfeeding times from the first breastfeeding to discharge in mothers who received Oketani massage was significantly higher than the participants in the control group who received the usual care. The duration of breastfeeding indicates breastfeeding success and, as an interactive process, will be followed by maternal satisfaction and meeting the baby's need (6).

The results of the present study suggested that Oketani massage can facilitate early breastfeeding after cesarean sections. Early initiation of breastfeeding is especially important for mothers undergoing a cesarean section and can play an important role in exclusive feeding and increasing the duration of breastfeeding (5).

This study also indicated that the average duration of breastfeeding after the mother was transferred to the recovery room was significantly shorter among the participants in the Oketani massage group compared to the members of the control group, while the duration of the first postoperative breastfeeding in the mothers who underwent cesarean sections is approximately three times greater compared to mothers with normal delivery (37), and this can have a negative effect on the acceptance of the mother's breast by the baby and the baby's sucking reflex (7).

The results of the study concerning the need for breastfeeding support suggested a statistically significant difference between the two groups in both breastfeeding rounds as the mothers in the intervention groups needed less support in the first and last breastfeeding before discharge compared to the participants in the control group. Oketani massage reduced the mother's need for support by influencing the way the infant latched onto the breast, the amount of audible swallowing noted, the mother's nipple type, and the mother's position of holding the infant while breastfeeding. However, previous studies in the literature have suggested that mothers who undergo cesarean sections need more support to start and 
continue breastfeeding, and the cesarean section is one of the most important risk factors for breastfeeding problems $(5,6,38)$.

A study by Dehghani et al. (2018) showed that Oketani massage has a greater relieving effect on the severity of breast congestion than conventional treatments (19). It seems that since postpartum breast congestion can be a barrier to timely breastfeeding and as mothers with breast congestion will need more support, Oketani breast massage can reduce breast congestion in mothers and thus diminishing their need for breastfeeding support. Furthermore, Jamzuri et al. (2019) and Kraleti et al. (2018) showed that Oketani massage increased the secretion of oxytocin and prolactin, increased blood circulation in the breasts, facilitated the exit of milk from the breast, and increased milk volume $(34,39)$, which, in general, can reduce the mother's need for support in breastfeeding.

The results of the present study indicated that the self-efficacy of mothers in the intervention group was significantly higher than those in the control group. Self-efficacy is one of the predictors and effective variables of exclusive breastfeeding and its continuation $(32,33)$ and refers to a person's belief in their ability to perform a specific task (40). Since the evidence shows that mothers' self-efficacy is related to the frequency, amount, and duration of breastfeeding $(42,41)$, Oketani massage may have a positive effect on the frequency and duration of breastfeeding by increasing the self-efficacy of the mother; a claim that requires

further attestation and research. One of the limitations of the present study was the use of self-report questionnaires for determining the mothers 'self-efficacy. Besides, mothers' characteristics, their mental status, and the level of spouse support are factors that could affect the success of breastfeeding, which were not addressed in this study.

\section{Conclusion}

The present study showed that Oketani massage has a positive effect on the breastfeeding success rate and can increase the number of breastfeeding times. It also reduces the breastfeeding onset time and facilitates early breastfeeding, reducing the mother's need for further support and improving her self-efficacy. Oketani massage can be performed as an independent and routine prophylactic intervention for all cesarean section mothers by nurses by completing a short training course. Therefore, it is recommended to teach this massaging 
technique to nurses and midwives who are in contact with the mother immediately before and after delivery to promote breastfeeding and reduce breastfeeding problems.

\section{Availability of data and materials}

The datasets used and analyzed during the current study are available from the corresponding author on reasonable request.

\section{Abbreviations}

IBFAT: Infant Breastfeeding Assessment Tool.

BSES: Breastfeeding Self-Efficacy Scale

WHO: World Health Organization

NIC: Nursing Interventions Classification

SPSS: Statistical Package for the Social Sciences

UNICEF: United Nations Children's Fund

\section{References}

1. Chen H, Tan D. Cesarean section or natural childbirth? A cesarean birth may damage your health. Frontiers in psychology. 2019;10:351.

2. Hejazi M. Comparison of personality characteristics and anxiety in pregnant women based on choosing the type of delivery. The Scientific Journal of Rehabilitation Medicine. 2018;7(1):51-8.

3. Kirca N, Adibelli D. Effects of the Delivery Type on the Breastfeeding Self-Efficacy Perception. International Journal of Caring Sciences. 2020;13(1):698.

4. Ladewig PW, London ML, Davidson MC. Contemporary maternal-newborn nursing: MACMILLAN HEINEMANN; 2013.

5. İsik Y, Dag ZO, Tulmac OB, Pek E. Early postpartum breastfeeding effects of cesarean and vaginal birth. Ginekologia Polska. 2016;87(6):426-30.

6. Kocaöz FŞ, Destegül D, Kocaöz S. Comparison of the breastfeeding outcomes and selfefficacy in the early postpartum period of women who had given birth by cesarean 
under general or spinal anesthesia. The Journal of Maternal-Fetal \& Neonatal Medicine. 2019:1-5.

7. Hobbs AJ, Mannion CA, McDonald SW, Brockway M, Tough SC. The impact of cesarean section on breastfeeding initiation, duration, and difficulties in the first four months postpartum. BMC pregnancy and childbirth. 2016;16(1):90.

8. Dehghani M, Babazadeh R, Khadivzadeh T, Pourhoseini SA, Esmaeili H. Effect of breast Oketani-massage on neonatal weight gain: a randomized controlled clinical trial. Evidence-Based Care. 2018;8(3):57-63.

9. Awaliyah SN, Rachmawati IN, Rahmah H. Breastfeeding self-efficacy as a dominant factor affecting maternal breastfeeding satisfaction. BMC nursing. 2019;18(1):30.

10. de Sá Guimarães CM, Conde RG, Gomes-Sponholz FA, Oriá MOB, dos Santos Monteiro JC. Factors related with breastfeeding self-efficacy immediate after birth in puerperal adolescents/Fatores relacionados à autoeficácia na amamentação no pós-parto imediato entre puérperas adolescentes. Acta Paulista de Enfermagem. 2017;30(1):109.

11. Rahmatnejad L, Bastani F. Factors associated with discontinuation of exclusive breastfeeding by first-time mothers. Iran Journal of Nursing. 2011;24(71):42-53.

12. Boateng GO, Martin SL, Tuthill EL, Collins SM, Dennis C-L, Natamba BK, et al. Adaptation and psychometric evaluation of the breastfeeding self-efficacy scale to assess exclusive breastfeeding. BMC pregnancy and childbirth. 2019;19(1):73.

13. Soti-Ulberg C, Hromi-Fiedler A, Hawley NL, Naseri T, Manuele-Magele A, Ah-Ching J, et al. Scaling up breastfeeding policy and programs in Samoa: application of the Becoming Breastfeeding Friendly initiative. International breastfeeding journal. 2020;15(1):1.

14. Cho J, Ahn HY, Ahn S, Lee MS, Hur M-H. Effects of Oketani breast massage on breast pain, the breast milk pH of mothers, and the sucking speed of neonates. Korean Journal of Women Health Nursing. 2012;18(2):149-58.

15. Oketani S. Oketani's breast massage therapy. Tokyo, Japan: Bong Hwang Dang Press; 1991. 
16. Kabir N, Tasnim S. Oketani breastfeeding management: A new method to augment breast milk. Journal of Bangladesh College of Physicians and Surgeons. 2009;27(3):155-9.

17. Ahn S, Kim J, Cho J. Effects of Breast Massage on Breast Pain, Breast-milk Sodium, and Newborn Suckling in Early Postpartum Mothers. Journal of Korean Academy of Nursing. 2011;41(4).

18. Foda MI, Kawashima T, Nakamura S, Kobayashi M, Oku T. Composition of milk obtained from unmassaged versus massaged breasts of lactating mothers. Journal of pediatric gastroenterology and nutrition. 2004;38(5):484-7.

19. Dehghani M, Babazadeh R, Khadivzadeh T, Azam Pourhosseini S, Esmaeili H. Effect of breast Oketani-massage on the severity of breast engorgement. The Iranian Journal of Obstetrics, Gynecology, and Infertility. 2017;20(5):30-8.

20. UNICEF. Protecting, promoting, and supporting breastfeeding in facilities providing maternity and newborn services: The revised Baby-Friendly Hospital Initiative. Implementation guidance. 2018. World Health Organization: Geneva. 2018.

21. Zhang F, Yang Y, Bai T, Sun L, Sun M, Shi X, et al. Effect of pumping pressure on the onset of breastfeeding after cesarean section: A randomized controlled study. Maternal \& child nutrition. 2018;14(1):e12486.

22. Srivastava S, Gupta A, Bhatnagar A, Dutta S. Effect of very early skin to skin contact on success at breastfeeding and preventing early hypothermia in neonates. Indian journal of public health. 2014;58(1):22.

23. Jensen D, Wallace S, Kelsay P. LATCH: a breastfeeding charting system and documentation tool. Journal of Obstetric, Gynecologic, \& Neonatal Nursing. $1994 ; 23(1): 27-32$.

24. Chapman DJ, Doughty K, Mullin EM, Pérez-Escamilla R. Reliability of breastfeeding assessment tools applied to overweight and obese women. Journal of Human Breastfeeding. 2016;32(2):269-76.

25. Altuntas N, Turkyilmaz C, Yildiz H, Kulali F, Hirfanoglu I, Onal E, et al. Validity and reliability of the infant breastfeeding assessment tool, the mother-baby assessment tool, and the LATCH scoring system. Breastfeeding Medicine. 2014;9(4):191-5. 
26. Karimi S, Najafi Kalyani M, Naghizadeh MM, Nekoee F, Kamali M. Comparison of Breastfeeding Patterns in Women with Normal Vaginal Delivery and Cesarean Section. The Iranian Journal of Obstetrics, Gynecology, and Infertility. 2011;14(6):46-53.

27. Matthews MK. Developing an instrument to assess infant breastfeeding behavior in the early neonatal period. Midwifery. 1988;4(4):154-65.

28. Adeli M, Alirezaei S, Kabiriyan M, Rafiei F. A comparison of the effect of short abdominal skin-to-skin contact and kangaroo skin contact on the initiation of successful breastfeeding. Journal of Babol University of Medical Sciences. 2018;20(2):70-6.

29. Beiranvand S, Valizadeh F, Hosseinabadi R, Pournia Y. The effects of skin-to-skin contact on temperature and breastfeeding success in full-term newborns after cesarean section. International Journal of pediatrics. 2014;2014.

30. SAH P, MS H. Comparison of the quality of breastfeeding in postpartum mothers undergone cesarean and vaginal delivery in selected military hospitals of Tehran. Military Caring Sciences Journal. 2017;4(1):70-9.

31. Dennis C-L, Heaman M, Mossman M. Psychometric testing of the breastfeeding selfefficacy scale-short form among adolescents. Journal of Adolescent Health. 2011;49(3):265-71.

32. Araban M, Mehrjardi FF, Shahry P, Montazeri A. The Persian version of breastfeeding self-efficacy scale-short form (BSES-SF): translation and psychometric assessment. Payesh (Health Monitor). 2016;15(1):87-93.

33. Moafi F, H Hajnasiri H, Hosseini T, Alimoradi Z, Bajalan Z. Breastfeeding self-efficacy and its associated factors in women who gave birth in Kosar Hospital of Qazvin in 2016-2017: A descriptive study. Journal of Rafsanjan University of Medical Sciences. 2019;17(11):1003-16.

34. Jamzuri M, Khayati N, Widodo S, Hapsari ED, Haryanti F. Increasing Oxytocin Hormone Levels in Postpartum Mothers Receiving Oketani Massage and Pressure in The GB-21 Acupressure Point. International Journal of Advancement in Life Sciences Research. 2019:22-7. 
35. Lim A-R, Song J-A, Hur M-H, Lee M-K, Lee MS. Cabbage compression early breast care on breast engorgement in primiparous women after cesarean birth: A controlled clinical trial. International journal of clinical and experimental medicine. 2015;8(11):21335.

36. Saatsaz S, Rezaei R, Alipour A, Beheshti Z. Massage as adjuvant therapy in the management of post-cesarean pain and anxiety: A randomized clinical trial. Complementary therapies in clinical practice. 2016;24:92-8.

37. Permatasari TAE, Syafruddin A. Early initiation of breastfeeding related to exclusive breastfeeding and breastfeeding duration in rural and urban areas in Subang, West Java, Indonesia. Journal of Health Research. 2016;30(5):337-45.

38. Wood NK. Home-Based Interventions in a Case of First Latch at 27 Days. Nursing for women's health. 2019;23(2):135-40.

39. Kraleti SK, Lingaldinna S, Kalvala S, Anjum S, Singh H. To study the impact of unilateral breast massage on milk volume among postnatal mothers-A quasiexperimental study. Indian Journal of Child Health. 2018:731-4.

40. Bandura A. Self-efficacy: toward a unifying theory of behavioral change. Psychological review. 1977;84(2):191.

41. Ngo LTH, Chou H-F, Gau M-L, Liu C-Y. Breastfeeding self-efficacy and related factors in postpartum Vietnamese women. Midwifery. 2019;70:84-91.

42. Brockway M, Benzies K, Hayden KA. Interventions to improve breastfeeding selfefficacy and resultant breastfeeding rates: a systematic review and meta-analysis. Journal of Human Breastfeeding. 2017;33(3):486-99.

43. Cambron, J. A., Dexheimer, J., Coe, P. \& Swenson, R. 2007. Side-effects of massage therapy: a cross-sectional study of 100 clients. The Journal of Alternative and Complementary Medicine, 13, 793-796.

44. Fogarty, S., Mcinerney, C., Stuart, C. \& Hay, P. 2019. The side effects and mother or child-related physical harm from massage during pregnancy and the postpartum period: an observational study. Complementary Therapies in Medicine, 42, 89-94. 
45. Yin, P., Gao, N., Wu, J., Litscher, G. \& Xu, S. 2014. Adverse events of massage therapy in pain-related conditions: a systematic review. Evidence-Based Complementary and Alternative Medicine, 2014.

46. Anderson, L., Kynoch, K. \& Kildea, S. 2016. Effectiveness of breast massage in the treatment of women with breastfeeding problems: a systematic review protocol. JBI database of systematic reviews and implementation reports, 14, 19-25.

47. Walker M. Breastfeeding Management for the Clinician. second ed2011

48. Agudelo S, Gamboa O, Rodríguez F, Cala S, Gualdrón N, Obando E, et al. The effect of skin-toskin contact at birth, early versus immediate, on the duration of exclusive human lactancy in full-term newborns treated at the Clínica Universidad de La Sabana: study protocol for a randomized clinical trial. Bio Med Central. 2016:2-9

\section{Acknowledgements}

We are thankful to all the mothers who participated and made this study feasible, to the hospitals involved in the study for the support provided during the conduction of this study.

\section{Funding}

This research did not receive any specific grant from funding agencies in the public, commercial, or not-for-profit sectors.

\section{Author information}

\section{Affiliations}

Department of Pediatric and Neonatal Nursing, School of Nursing and Midwifery, Shahid Beheshti University of Medical Sciences, Tehran, Iran

Maryam Mahdizadeh Shahri, Manijeh Nourian, Maryam Varzeshnejad, Maliheh Nasiri.

\section{Competing interests}

The authors declare that they have no competing interests.

\section{Authors' contributions}

MMSh was responsible for the study design, data collection, transcription, and manuscript drafting. MNo conceived the study, reviewed and revised the manuscript and were involved in the study design and development and reviewed the manuscript and approved the final version for submission. 
MVa Searched, critically analyzed the manuscript for scientific logic and reasoning and provided critical comments on this paper. MNa conducted the data analysis. All authors read and approved the final manuscript.

\section{Corresponding author}

Correspondence to Manijeh Nourian

\section{Ethics declarations}

Ethical approval was approved by the ethics committees of the school of pharmacy and nursing and midwifery shahid beheshti university of medical sciences.

registration number IR.SBMU.PHARMACY.REC.1399.110.

Date of approval: Jul 6, 2020

\section{Consent for publication}

Not applicable. 


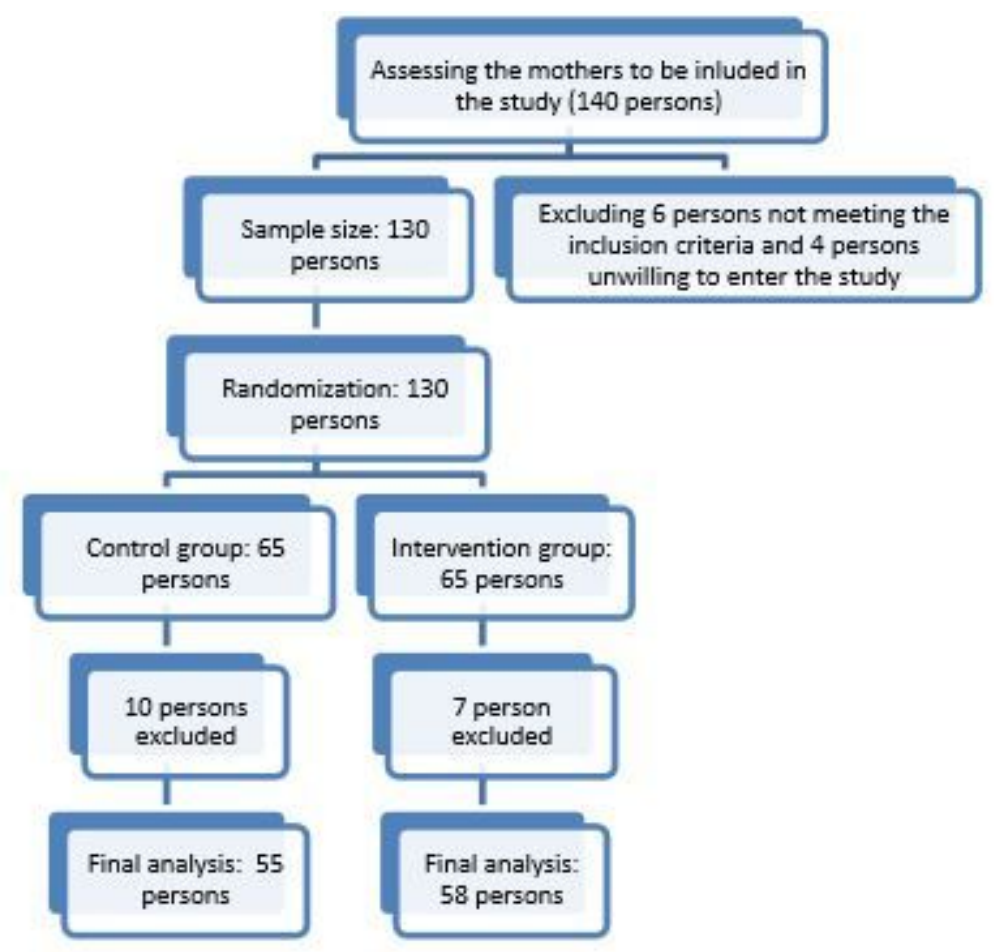

Figure 1

The participants' selection flowchart 